\title{
Evaluating the Effectiveness of a Six-Day Residential Summer Program for Underrepresented Students
}

\section{Ms. Reyna M. Flores, University of Texas, Austin}

Reyna is the Recruitment Coordinator for the Equal Opportunity in Engineering (EOE) Program at the University of Texas at Austin. The EOE Program strives to recruit, retain, and graduate underrepresented students in the Cockrell School of Engineering. For over five years, Reyna has worked to support underrepresented students reach their higher education goals through various college access programs in the state of Texas.

\section{Mr. Enrique Dominguez, University of Texas, Austin}

Mr. Enrique Dominguez is the Director of the Equal Opportunity in Engineering Program at the Cockrell School of Engineering at the University of Texas at Austin. He has been Director for over 4 years and is currently the Region D Chair for the National Association for Multicultural Engineering Program Advocates (NAMEPA). Enrique graduated from the Cockrell School of Engineering with a Civil Engineering degree and pursued industry experience for seven years where he held positions such as Project Engineer, Lead University Recruiter, Logistics Engineer, Cost Engineer and Project Manager. 
Evaluating the Effectiveness of a Six-Day Residential Summer Program for Underrepresented High School Students 


\section{Introduction}

The educational achievement gap in Science, Technology, Engineering, and Mathematics (STEM) disciplines in America continue to persist among underrepresented groups [7]. Underrepresented groups include Hispanics, African American, Native American, and Native Hawaiian students. While underrepresented student enrollment has been increasing in secondary schools, the achievement gap in STEM widens as students' progress from kindergarten to high school [5]. Underrepresented minority students face more barriers from persistence to graduation [3]. The achievement gap is compounded over time and when underrepresented students reach high school, they are not prepared to take the challenging courses that colleges expect of prospective engineering students [6].

The most effective way to turn things around is to provide coursework in middle and high school to give students a sense of what STEM courses entail at the college level [1]. The $\mathrm{K}-12$ pipeline is expected to have an inevitable majority of underrepresented minorities and should be a major focal point of intervention to cultivate the diverse talent pool needed to sustain the nation's future in STEM [5]. There is a lack of STEM awareness and programming in the K-12 pipeline in targeted high schools, but a large need for STEM in the workforce [5]. One current approach to address the achievement gap is the implementation of the MITE Enrichment Program at The University of Texas at Austin. MITE provides the opportunity to discover engineering through faculty-led sessions for high school juniors at the Cockrell School of Engineering at the UT Austin. It also serves as a recruitment strategy to increase the number of underrepresented minority groups.

\section{History of the EOE Program}

The Cockrell School of Engineering established the EOE program in 1970 to promote the recruitment and academic development of African American, Hispanic, and Native American students interested in pursuing careers in engineering. Since that time, the EOE program has expanded its goals and now seeks to increase the diversity of its student body (i.e. first-generation, low socioeconomic status, LGBTQ, veterans, etc.) by supporting students who come from historically underrepresented population groups in Texas or students who have backgrounds or experiences that will contribute to the overall diversity of the Cockrell School of Engineering.

The EOE program initiatives help students establish a strong academic foundation and promote the formation of a peer support network. In addition, it provides students with access to tutoring, undergraduate research opportunities, and professional development workshops.

The University of Texas at Austin ranks third in the nation in producing undergraduate engineering degrees for minority groups [2]. EOE is financially supported by the Cockrell School of Engineering, corporate partners, and grants from federal and state governments. 
Mission

The EOE program promotes excellence in the areas of academics, leadership, professionalism, and community support; develops pre-college and college students on their academic journey; and builds a support network for advancement through opportunities that encourages engineering students to interact with their peers, faculty, alumni, and corporate representatives.

Vision

The EOE program's vision is to create a student body at the Cockrell School of Engineering and the University of Texas at Austin that reflects the diversity of the college-age population within Texas.

\section{About MITE Enrichment Program}

Formerly known as the MITE Summer Camp, established in the 1980s, the program strived to increase the number of minority students in engineering by inviting 100 students to the UT Austin campus to become excited about engineering.

The MITE Enrichment Program is a free, six-day residential program that offers current high school juniors the opportunity to discover engineering through hands-on projects and interactions with engineering students, faculty, staff and alumni. MITE is open to students with strong interests in engineering, science or math. Two sessions are held in the month of June and fifty students are selected to attend each session. Outstanding African-American, Hispanic, Native American and Native Hawaiian students, as well as those who have overcome any social or economic hardship, are strongly encouraged to apply. All students are welcome to apply. Students must reside in the United States. Student participants are housed in a campus dorm. All program expenses (including housing and food) are paid for, with the exception of travel to and from the university.

The MITE application mirrors the required university application for the fall semester. The application requires an online application, essay, resume, counselor recommendation, STEM teacher recommendation, official high school transcript, and parent acknowledgement form. An average of 300 applications are submitted each year over the last ten years. Students receive emails about the MITE Enrichment Program via the university's recruitment database. The Recruitment Coordinator of the EOE program also sends emails to high school teachers, counselors, and staff at targeted high schools.

Attending the MITE Enrichment Program is one of the best ways to learn more about engineering at the University of Texas at Austin. As a MITE participant, students have the opportunity to interact with engineering student leaders, distinguished faculty, and dedicated staff members. Students also gain insight into what life is like as an engineering student. During the day, students learn about undergraduate engineering disciplines at UT Austin through lectures given by faculty. MITE counselors, who are current engineering students, serve as mentors to their teams and give various tours of the 
campus and engineering labs. Student teams work on a chain reaction machine project each evening, and present and run their machine on the last day of the program. Students acquire the vision of the true college experience by living on-campus. Students also learn about admissions and financial aid.

Students complete an evaluation at the end of the MITE Enrichment Program. The evaluation assesses students' desire to study engineering in college, which engineering discipline they wish to pursue at UT Austin, the likelihood of applying to the university, and other learning outcomes. MITE participants are tracked for multiple years to determine how many apply, receive acceptance, and enroll into the Cockrell School of Engineering. Program evaluation considers data of the MITE Enrichment Program over a period of forty-four years and reviews recruitment trends related to underrepresented students in engineering.

\section{Recruiting Strategies}

There is a lack of STEM awareness and programming in the K-12 pipeline in targeted high schools, but a large need for STEM in the workforce [5]. To increase the efforts of recruitment to the STEM fields, students should be exposed to STEM at a younger age [1]. The MITE Enrichment Program serves as a way to educate and expose underrepresented high school students to engineering.

The MITE Enrichment Program mimics recruiting efforts of UT Austin, while focusing on underrepresented populations in Texas. The university targets specific groups to fulfill its mission of diversity. The university reaches out to high schools that typically yield low enrollment to the university but are extremely diverse. Other targeted schools include magnet high schools, inter-city schools, early college high schools, and STEM high schools. The EOE program has a mailing list of teachers, staff, and administration at targeted high schools who receive information about the MITE program.

\section{Financial Information of the MITE Enrichment Program}

The EOE program is primarily externally funded. Grants, corporate donors, and philanthropic giving fund the MITE Enrichment Program. Grants consist of 48 percent, corporate donors make up 42 percent, and philanthropic giving is 10 percent of the MITE budget.

The MITE Enrichment Program has a budget of forty thousand dollars for both MITE weeks. Housing and meals on campus account for half of the budget. Counselors' pay is about one-quarter of the budget. Food is catered for Thursday's dinner with alumni and industry representatives and Friday's closing ceremony with families. Bowling and team building activities are included in the cost of catering. The supplies include t-shirts and lanyards for all participants and counselors, items for the project, and prizes for first, second, and third place teams. Risk insurance covers participants and staff in case of an emergency during the MITE Enrichment Program. The extra housing week is the cost of 
the housing for counselors who stayed on campus during the week in between the MITE sessions for 2016.

The average cost per student is about four hundred dollars to attend. The cost per student can fluctuate year to year. The MITE Enrichment Program aims to have fifty students attend each week.

\begin{tabular}{|l|r|}
\hline \multicolumn{2}{|c|}{ MITE 2016 Budget } \\
\hline Room and Board & $\$ 19,500$ \\
\hline Counselors' Pay & $\$ 10,600$ \\
\hline Catering & $\$ 4,300$ \\
\hline Supplies & $\$ 1,885$ \\
\hline Risk Insurance & $\$ 675$ \\
\hline Extra Housing Week & $\$ 400$ \\
\hline \multicolumn{1}{|c|}{ Total } & $\$ 37,360$ \\
\hline
\end{tabular}

\section{Schedule of the MITE Enrichment Program}

Students participate in a six-day schedule, including faculty presentations and creating their MITE machine projects.

Sample Schedule

\begin{tabular}{|c|c|c|c|c|c|c|c|}
\hline & Sunday & Monday & Tuesday & Wednesday & Thursday & Friday & \\
\hline $6: 00 a-6: 30 a$ & & \multirow{3}{*}{$\begin{array}{l}\text { Wake Up / Prep } \\
\text { for the day }\end{array}$} & \multirow{3}{*}{$\begin{array}{l}\text { Wake Up / Prep } \\
\text { for the day }\end{array}$} & \multirow{3}{*}{$\begin{array}{l}\text { Wake Up / Prep } \\
\text { for the day }\end{array}$} & \multirow{3}{*}{$\begin{array}{l}\text { Wake Up / Prep } \\
\text { for the day }\end{array}$} & \multirow{3}{*}{$\begin{array}{l}\text { Wake Up / Prep } \\
\text { for the day }\end{array}$} & $6: 00 a-6: 30 a$ \\
\hline $6: 30$ - 7:00 & & & & & & & $6: 30-7: 00$ \\
\hline $7: 00 a-7: 30 a$ & & & & & & & 7:00a - 7:30a \\
\hline 7:30 - 8:00 & & \multirow{3}{*}{ BREAKFAST } & \multirow{3}{*}{ BREAKFAST } & \multirow{3}{*}{ BREAKFAST } & \multirow{3}{*}{ BREAKFAST } & \multirow{3}{*}{ BREAKFAST } & $7: 30$ - 8:00 \\
\hline $8: 00 a-8: 30 a$ & & & & & & & $8: 00 a-8: 30 a$ \\
\hline $8: 30$ - 9:00 & & & & & & & $8: 30-9: 00$ \\
\hline $9: 00 a-9: 30 a$ & & \multirow{6}{*}{$\begin{array}{c}\text { Machine - Intro \& } \\
\text { Activities }\end{array}$} & \multirow{6}{*}{$\begin{array}{l}\text { Chemical } \\
\text { Engineering and } \\
\text { Study Abroad }\end{array}$} & \multirow{6}{*}{$\begin{array}{c}\text { Mechanical } \\
\text { Engineering and } \\
\text { Admissions }\end{array}$} & \multirow{6}{*}{$\begin{array}{c}\text { Aerospace } \\
\text { Engineering and } \\
\text { Financial Aid }\end{array}$} & \multirow{4}{*}{$\begin{array}{l}\text { MITE Machine } \\
\text { Set-up and Run }\end{array}$} & 9:00a - 9:30a \\
\hline $9: 30-10: 00$ & & & & & & & 9:30 - 10:00 \\
\hline \multicolumn{2}{|l|}{$10: 00 a-10: 30 a$} & & & & & & $10: 00 a-10: 30 a$ \\
\hline $10: 30-11: 00$ & & & & & & & $10: 30-11: 00$ \\
\hline 11:00a - 11:30a & & & & & & \multirow{4}{*}{$\begin{array}{c}\text { MITE Machine } \\
\text { Awards }\end{array}$} & $11: 00 a-11: 30 a$ \\
\hline $11: 30-12: 00$ & & & & & & & $11: 30-12: 00$ \\
\hline \multicolumn{2}{|l|}{$12: 00 p-12: 30 p$} & \multirow{2}{*}{ LUNCH } & \multirow{2}{*}{ LUNCH } & \multirow{2}{*}{ LUNCH } & \multirow{2}{*}{ LUNCH } & & 12:00p-12:30p \\
\hline $12: 30-1: 00$ & & & & & & & $12: 30-1: 00$ \\
\hline $1: 00 p-1: 30 p$ & & \multirow{9}{*}{$\begin{array}{l}\text { Lab Tours, Civil } \\
\text { Engineering, } \\
\text { Calculus }\end{array}$} & \multirow{9}{*}{$\begin{array}{c}\text { Resumes and } \\
\text { Biomedical } \\
\text { Engineering }\end{array}$} & \multirow{9}{*}{$\begin{array}{l}\text { Essays and } \\
\text { Petroleum } \\
\text { Engineering }\end{array}$} & \multirow{4}{*}{$\begin{array}{c}\text { Electrical } \\
\text { Engineering }\end{array}$} & Check out of & $1: 00 p-1: 30 p$ \\
\hline $1: 30-2: 00$ & \multirow{2}{*}{ Check in } & & & & & Dorms & $1: 30-2: 00$ \\
\hline $2: 00 p-2: 30 p$ & & & & & & & 2:00p - 2:30p \\
\hline $2: 30$ - 3:00 & \multirow{4}{*}{ Orientation } & & & & & & $2: 30$ - 3:00 \\
\hline $3: 00 p-3: 30 p$ & & & & & & & 3:00p - 3:30p \\
\hline $3: 30-4: 00$ & & & & & & & $3: 30-4: 00$ \\
\hline $4: 00 p-4: 30 p$ & & & & & MITE Machine & & $4: 00 p-4: 30 p$ \\
\hline 4:30 - 5:00 & & & & & Presentations & & $4: 30-5: 00$ \\
\hline $5: 00 p-5: 30 p$ & leam Bullang & & & & & & $5: 00 p-5: 30 p$ \\
\hline $5: 30-6: 00$ & & & & & & & $5: 30-6: 00$ \\
\hline $6: 00 p-6: 30 p$ & & & & & & & 6:00p - 6:30p \\
\hline $6: 30$ - 7:00 & Bowling & DINNER & DINNER & DINNER & Alumnı Panel & & $6: 30-7: 00$ \\
\hline $7: 00 p-7: 30 p$ & & & & & & & $7: 00 p-7: 30 p$ \\
\hline 7:30 - 8:00 & MITF Proiest & & & & & & 7:30 - 8:00 \\
\hline $8: 00 p-8: 30 p$ & & & & & DINNER & & $8: 00 p-8: 30 p$ \\
\hline $8: 30$ - 9:00 & & MII IE Machıne & MIIE Machıne & MII I I Machıne & & & $8: 30-9: 00$ \\
\hline $9: 00 p-9: 30 p$ & DINNER & & & & Online & & 9:00p - 9:30p \\
\hline $9: 30-10: 00$ & & & & & Evaluations & & $9: 30-10: 00$ \\
\hline 10:00p - 10:30p & & & & & & & $10: 00 p-10: 30 p$ \\
\hline \begin{tabular}{|l|}
$10: 30-11: 00$ \\
\end{tabular} & Room checks & Room Checks & Room Checks & Room checks & Room checks & & $10: 30-11: 00$ \\
\hline
\end{tabular}


The first day of MITE is check-in and orientation. Parents remain with their student during orientation then separate to have their own time to discuss policies and structure of the program. Meanwhile, students meet their team members and MITE counselor. A series of team building activities take place to have students get to know each other and boost team collaboration.

After team building activities, students learn about their machine project. Each team receives a binder with information about each person's role in the team, budget forms, rules, and grading matrices. One role is to use the Maker Space to create an item for the machine project. This team member learns about the Maker Space and becomes familiar with the process for creating and printing a 3-D item.

During the week, students participate in lab tours and presentations from faculty, student services, and admissions. Staff members assist with reviewing students' resumes and essays and provide feedback. Various student services, such as the engineering career center and study abroad, speak to students during the week. Students become familiar with engineering facilities that the Cockrell School of Engineering has to offer and learn about the process for applying to UT Austin.

Students also learn about faculty's research. Because of their many roles, including advisors and mentors to students, faculty can affect both minority engineering programs and student retention levels [4]. Therefore, it is important to gain support from faculty, especially minority faculty, who create relationships with students who look like and can relate to them.

The University of Texas at Austin has a Youth Protection Policy that the MITE Enrichment Program must adhere to during the week. The policy ensures the safety on minors participating in camps or programs on university premises or participating in those programs sponsored or supported by the university.

\section{Statistics of the MITE Enrichment Program}

The EOE program has forty-four years of MITE data. However, to keep this paper concise, this section will review the last ten years of data. As high school juniors at the time of the MITE Enrichment Program, participants are expected to enroll at UT Austin the fall semester of the next year. For example, MITE 2004 participants enroll in the fall of 2005 .

The following chart shows the data for each MITE from 2004 to 2014 for enrollment years of fall 2005 to fall 2015. Percentages are also included for each enrollment year:

- Percentage of participants applied out of the total number of participants

- Percentage of accepted to the university out of the number of participants applied

- Percentage of participants enrolled out of the number of participants accepted

- Percentage of participants enrolled to the Cockrell School of Engineering out of total enrolled 


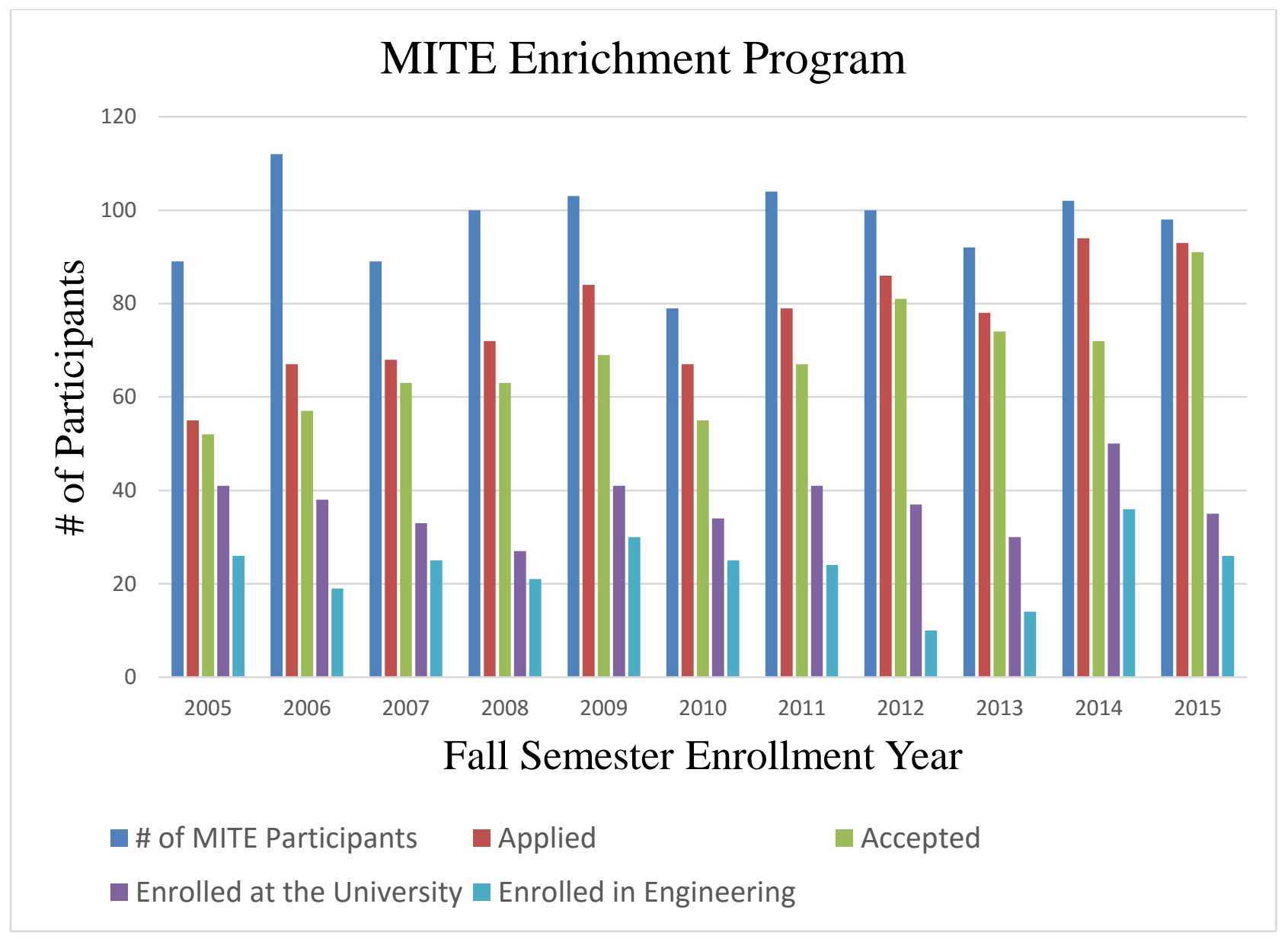

Fall 2005 potential enrollment pool of MITE 2004 participants was 89 students:

○ $62 \%$ applied to UT Austin (55)

- $\quad 95 \%$ were accepted (52)

- $79 \%$ enrolled into UT Austin (41)

○ $63 \%$ enrolled into Cockrell School of Engineering (26)

Fall 2006 potential enrollment pool of MITE 2005 participants was 112 students:

○ $60 \%$ applied to UT Austin (67)

- $85 \%$ were accepted (57)

- $\quad 67 \%$ enrolled into UT Austin (38)

○ $50 \%$ enrolled into Cockrell School of Engineering (19)

Fall 2007 potential enrollment pool of MITE 2006 participants was 89 students:

○ $\quad 76 \%$ applied to UT Austin (68)

- $93 \%$ were accepted (63)

○ $52 \%$ enrolled into UT Austin (33)

- $76 \%$ enrolled into Cockrell School of Engineering (25)

Fall 2008 potential enrollment pool of MITE 2007 participants was 100 students:

- $72 \%$ applied to UT Austin (72)

- $88 \%$ were accepted (63)

- $43 \%$ enrolled into UT Austin (27)

○ $78 \%$ enrolled into Cockrell School of Engineering (21) 
Fall 2009 potential enrollment pool of MITE 2008 participants was 103 students:

○ $82 \%$ applied to UT Austin (84)

- $82 \%$ were accepted (69)

- $59 \%$ enrolled into UT Austin (41)

- $73 \%$ enrolled into Cockrell School of Engineering (30)

Fall 2010 potential enrollment pool of MITE 2009 participants was 79 students:

- $85 \%$ applied to UT Austin (67)

○ $82 \%$ were accepted (55)

- $62 \%$ enrolled into UT Austin (34)

- $74 \%$ enrolled into Cockrell School of Engineering (25)

Fall 2011 potential enrollment pool of MITE 2010 participants was 104 students:

○ $76 \%$ applied to UT Austin (79)

- $85 \%$ were accepted (67)

- $61 \%$ enrolled into UT Austin (41)

- $59 \%$ enrolled into Cockrell School of Engineering (24)

Fall 2012 potential enrollment pool of MITE 2011 participants was 100 students:

○ $86 \%$ applied to UT Austin (86)

- $94 \%$ were accepted (81)

- $46 \%$ enrolled into UT Austin (37)

- $27 \%$ enrolled into Cockrell School of Engineering (10)

Fall 2013 potential enrollment pool of MITE 2012 participants was 92 students:

○ $85 \%$ applied to UT Austin (78)

- $95 \%$ were accepted (74)

- $41 \%$ enrolled into UT Austin (30)

- $47 \%$ enrolled into Cockrell School of Engineering (14)

Fall 2014 potential enrollment pool of MITE 2013 participants was 102 students:

○ $92 \%$ applied to UT Austin (94)

○ $65 \%$ were accepted (61)

- $77 \%$ enrolled into UT Austin (47)

○ $\quad 77 \%$ enrolled into Cockrell School of Engineering (36)

Fall 2015 potential enrollment pool of MITE 2014 participants was 98 students:

○ $95 \%$ applied to UT Austin (93)

- $93 \%$ were accepted (86)

○ $41 \%$ enrolled into UT Austin (35)

○ $74 \%$ enrolled into Cockrell School of Engineering (26)

\section{MITE Trends}

The number of MITE participants remains around 100 each year; however, participants' application, acceptance, and enrollment data varies year to year. Application rates have increased over time. It is important to note that participation in the MITE Enrichment Program does not give a high school student an advantage in admission to the University of Texas at Austin. The Office of Admissions handles admission decisions to the university and to the Cockrell School of Engineering. The enrollment rate of underrepresented students in the Cockrell School has remained around twenty percent. 


\section{Evaluations}

Students complete an evaluation at the end of the MITE Enrichment Program. The evaluation assesses students' likelihood of applying to the University of Texas at Austin, desire to study engineering in college, if participation in MITE has increased interest in UT Austin, if participation in MITE has led to a better understanding of engineering, and more. MITE participants are tracked for multiple years to determine how many apply, receive acceptance, and enroll into the Cockrell School of Engineering.

For the purpose of this paper, MITE evaluation data has remained consistent and therefore include the most recent evaluation results. These are the evaluation results from the most recent MITE Enrichment Program. Ninety-five high school juniors attended.

56 students $(59 \%)$ selfidentified as underrepresented minority students.

\begin{tabular}{l}
\multicolumn{3}{c}{$\begin{array}{c}\text { MITE } 2016 \text { participants by ethnicity (based on evaluation } \\
\text { responses) }\end{array}$} \\
\begin{tabular}{|l|c|r|}
\hline \multicolumn{2}{|l|}{ Race/Ethnicity } & $\%$ \\
\hline Hispanic or Latino & 37 & $39 \%$ \\
\hline American Indian or Alaska Native & 2 & $2 \%$ \\
\hline African American / Black & 14 & $15 \%$ \\
\hline Asian & 36 & $38 \%$ \\
\hline $\begin{array}{l}\text { Native Hawaiian or Other Pacific } \\
\text { Islander }\end{array}$ & 3 & $3 \%$ \\
\hline Caucasian / White & 45 & $47 \%$ \\
\hline Total & 95 & $100 \%$ \\
\hline
\end{tabular}
\end{tabular}

About one third of MITE participants were female.

\begin{tabular}{|l|c|c|}
\hline \multicolumn{3}{|c|}{ MITE 2016 participants by gender } \\
Gender & \# Participants & $\%$ \\
\hline Male & 61 & $64 \%$ \\
\hline Female & 34 & $36 \%$ \\
\hline Total & 95 & $100 \%$ \\
\hline
\end{tabular}

MITE 2016 participant responses to "the likelihood that I will apply to the University of Texas at Austin": 97 percent of students agreed or strongly agreed that they will apply to the university.

\begin{tabular}{|l|c|r|}
\hline Response & \# Participants & $\%$ \\
\hline $100 \%$ & 83 & $87 \%$ \\
\hline $75 \%$ & 9 & $10 \%$ \\
\hline $50 \%$ & 2 & $2 \%$ \\
\hline $25 \%$ & 1 & $1 \%$ \\
\hline $0 \%$ & 0 & $0 \%$ \\
\hline \hline Total & 95 & $100 \%$ \\
\hline
\end{tabular}


MITE 2016 participant response to "the likelihood that I will major in engineering":

About 85 percent of students agreed or strongly agreed that they will likely major in engineering.

\begin{tabular}{|l|c|r|} 
Response & \# Participants & \multicolumn{1}{c|}{$\%$} \\
\hline $100 \%$ & 48 & $50.5 \%$ \\
\hline $75 \%$ & 33 & $35 \%$ \\
\hline $50 \%$ & 11 & $11.5 \%$ \\
\hline $25 \%$ & 3 & $3 \%$ \\
\hline $0 \%$ & 0 & $0 \%$ \\
\hline \hline Total & 95 & $100 \%$ \\
\hline
\end{tabular}

MITE 2016 participant response to "My participation in MITE has increased my interest in attending UT Austin." 96 percent of students agreed or strongly agreed that the MITE Enrichment Program increased their interest to attend the university.

MITE 2016 participant response to "My participation in MITE has led me to a better understanding of the field of engineering." 99 percent of students say that MITE has led them to a better understanding of engineering.

\begin{tabular}{|l|c|r|}
\hline Response & \# Participants & \multicolumn{1}{c}{$\%$} \\
\hline Strongly Agree & 62 & $65 \%$ \\
\hline Agree & 29 & $31 \%$ \\
\hline Neutral & 2 & $2 \%$ \\
\hline Disagree & 2 & $2 \%$ \\
\hline Strongly Disagree & 0 & $0 \%$ \\
\hline Total & 95 & $100 \%$ \\
\hline
\end{tabular}

\begin{tabular}{|l|c|r|}
\hline Response & \# Participants & \multicolumn{1}{c|}{$\%$} \\
\hline Strongly Agree & 76 & $80 \%$ \\
\hline Agree & 18 & $19 \%$ \\
\hline Neutral & 1 & $1 \%$ \\
\hline Disagree & 0 & $0 \%$ \\
\hline Strongly Disagree & 0 & $0 \%$ \\
\hline \hline Total & 95 & $100 \%$ \\
\hline
\end{tabular}

MITE 2016 participant response to "My participation in MITE sparked my interest or increased my desire to study engineering in college."

88 percent say MITE sparked their interest or desire to study engineering in college.

\begin{tabular}{|l|c|r|}
\hline Response & \# Participants & \multicolumn{1}{c|}{$\%$} \\
\hline Strongly Agree & 58 & $61 \%$ \\
\hline Agree & 26 & $27 \%$ \\
\hline Neutral & 9 & $10 \%$ \\
\hline Disagree & 1 & $1 \%$ \\
\hline Strongly Disagree & 1 & $1 \%$ \\
\hline Total & 95 & $100 \%$ \\
\hline
\end{tabular}


Direct Quotes from MITE 2016 Evaluation

"The alumni panel was great, it really made me interested in coming to this school. I also really enjoyed hearing lectures from professors who are so knowledgeable in the field and hearing them share their information with us. I also made many friends, and although we are going separate ways soon, the experiences have been indispensable."

"The best experience this week was being able to see an array of engineers within their labs and being able to hear of their research."

"[The best experience I had was] being inspired by the Maker Space. It makes me want to come here and just play around and design and make things."

"The best part of the week was touring labs, meeting professors and listening to their lectures. It really gave me a good idea of the research that an engineer with a $\mathrm{PhD}$ can do and made me more confident in pursuing engineering."

"The best experience I had this week was to be able to work with my team on the project and also the games provided by the counselors."

\section{Best Practices and Positive Improvements for the Future}

One of the goals of the MITE Enrichment Program is to give prospective students a realistic sense of being an engineering student in college. From the schedule to the teamoriented project, the MITE Enrichment Program has evolved with decades of experience. The MITE schedule gives students an idea of how to manage their time as an engineering student. Participants of the MITE Enrichment Program wake up early and stay busy all day with presentations, lab tours, and the MITE machine project. The schedule reflects a normal engineering student's daily routine.

A team-oriented project has been a part of the schedule since its first year. The MITE project is a team-oriented project that gives MITE participants insight into collaborating with others. Each team member has a different role and are in charge of completing tasks, such as the budget and design. The team must work together to successfully complete their project. At the end of the week, students present their project and run their machine.

In its early years, MITE quickly learned to have one male and one female staff. The EOE program hires current engineering students as counselors to be with the students during the day and stay with them on campus overnight. They serve as mentors to prospective students and have the first-hand experience that prospective students want to know. Counselors also have their own group of students to work with and guide as they work on their MITE project. A Head Counselor is in charge of the counselors and oversees the group interaction and flow of the program. 
In the last decade, alumni and industry representatives have participated in judging the presentations. One evening, MITE participants have the opportunity to hear from an alumni panel and network with them at a dinner following the presentations. This allows participants to learn more about the field of engineering from someone that they can relate to and receive advice about work-related experiences.

The MITE Enrichment Program is intended to serve as a recruitment strategy. In 2012, MITE required students to be high school juniors, instead of having it open to eligible sophomores and juniors. As high school juniors, students learn about the various majors offered at the University of Texas at Austin. The MITE Enrichment Program helps them identify interest in an engineering major and prepares participants for their college application process to UT Austin. Once students return to their high schools and become seniors, they have a sense of what major to select when applying. This grade level requirement change helped the track MITE participants as a cohort for application, admission, and enrollment statistics.

In 2014, the EOE program learned that the term "summer camp" was the most common term searched on the university's website. This is when MITE officially changed to MITE Enrichment Program, instead of MITE summer camp. As a summer camp, parents often asked to drop off their students and were willing to pay for their students to attend, even though MITE is free. The term "summer camp" did not attract our intended student population. Changing of the name disassociated the MITE Enrichment Program from other traditional summer camps offered at UT Austin.

For MITE 2015, the EOE program increased the number of admitted MITE participants from 100 to 150. Seventy-five students were admitted to each week of MITE. Several challenges arose due to the increase, including reserving rooms large enough to fit the group size. Though more counselors were hired, the MITE participant group was difficult to manage and navigate throughout campus. Another challenge was eating at the dining halls on campus. The MITE Enrichment Program has decided that fifty students for each week is an ideal size.

Until 2016, the MITE Enrichment Program had always been two consecutive weeks. MITE counselors, current engineering students, voiced their concern with having a break in between the two weeks. MITE is an intense week for participants and more of a burden for counselors who stay up late and wake up earlier. For the summer of 2016, the EOE program decided to plan a one-week break in between the two MITE sessions. This gave counselors and staff members a mental break and time to refresh for the second week of MITE. However, more money was needed towards the housing budget to pay for an extra one week of on-campus housing for counselors.

A future idea for MITE is creating an on-the-road experience for students in Texas who cannot travel to the University of Texas at Austin. Target areas are the southernmost region of the state and the eastern region. The ideal plan is to host students at a local high school and bring the university experience to them with a one-day field trip to the university at the end of the week. This will increase exposure of the Cockrell School of 
Engineering to high school students who do not have the means to travel to the university.

\section{Conclusion}

The EOE program was established by the Cockrell School of Engineering to promote the recruitment and academic development of African American, Hispanic, and Native American students interested in pursuing careers in engineering. The EOE program created the MITE Enrichment Program for high school students to learn more about the Cockrell School of Engineering at the University of Texas at Austin. The MITE Enrichment Program serves as a recruitment tool to increase the number of underrepresented students at the Cockrell School of Engineering. In 2016, the Cockrell School of Engineering was ranked third in producing minority engineering graduates in the nation and ranked first in the state of Texas [2]. The EOE program and the Cockrell School of Engineering continue to serve MITE participants if they decide to enroll at the University of Texas at Austin.

Over time, MITE participants' application rates have increased. Acceptance and enrollment rates into the University of Texas at Austin of MITE participants have varied year to year. The enrollment rate of underrepresented students in the Cockrell School of Engineering has remained around twenty percent. Through MITE, the EOE program will continue to strive for diversity. The EOE program's vision is to create a student body at the Cockrell School of Engineering and the University of Texas at Austin that reflects the diversity of the college-age population within Texas. 


\section{References}

[1] Abdul-Alim, J. (2013). Why Are the Underrepresented Minorities Underachieving in STEM? Diverse Issues in Higher Education.

[2] Cox, Mathews, and Associates, Inc. (2016). Top 100 Degree Producers 2016: Baccalaureate. Diverse Issues in Higher Education.

[3] Huang, G., et al. (2000). Entry and Persistence of Women and Minorities in College Science and Engineering, National Center for Education Statistics (NCES 2000-601). Washington, DC: U.S. Department of Education.

[4] Landis, R. B. (1985). Improving the Retention and Graduation of Minorities in Engineering. NACME and NAMEPA Handbook.

[5] National Academy of Sciences, National Academy of Engineering, and Institute of Medicine. (2011). Expanding Underrepresented Minority Participation: America's Science and Technology Talent at the Crossroads. Washington, DC: The National Academies Press.

[6] National Action Council for Minorities in Engineering. (2014). Pre-College Challenges for URMs in Engineering. Research and Policy.

[7] Verdell, A. C., \& Keith, J. M., \& Warnock, J., \& White, V. M. (2016, June). Best Practices for Underrepresented Minority Students in an Engineering Summer Bridge Program Paper presented at 2016 ASEE Annual Conference \& Exposition, New Orleans, Louisiana. 